\title{
The Intrapersonal Functions of Emotion
}

\author{
Robert W. Levenson \\ University of California-Berkeley, USA
}

\section{INTRODUCTION}

A few years back, I (Levenson, 1994) tried to answer the question: "What are the functions of emotion?" The opening paragraph (p. 123) of my response still captures the essence of my view:

Emotions are short-lived psychological-physiological phenomena that represent efficient modes of adaptation to changing environmental demands. Psychologically, emotions alter attention, shift certain behaviors upward in response hierarchies, and activate relevant associative networks in memory. Physiologically, emotions rapidly organize the responses of disparate biological systems including facial expression, somatic muscular tonus, voice tone, autonomic nervous system activity, and endocrine activity to produce a bodily milieu that is optimal for effective response. Emotions serve to establish our position vis-à-vis our environment, pulling us toward certain people, objects, actions and ideas, and pushing us away from others. Emotions also serve as a repository for innate and learned influences, possessing certain invariant features, and others that show considerable variation across individuals, groups, and cultures.

In this article I will revisit this issue in greater depth, starting by presenting a two-system functional model of the emotion system, and then applying this hypothetical model to discuss the following topics related to the intrapersonal functions of emotion: (1) coping with environmental challenges; (2) the "undoing" function of positive emotions; (3) shifting behavioural and cognitive hierarchies; (4) subjective experience;

Requests for reprints should be sent to Dr Robert W. Levenson, Department of Psychology, 3210 Tolman Hall No. 1650, University of California-Berkeley, CA 94720-1650, USA.

Preparation of this article has been supported by grants to the author from the National Institute of Mental Health (MH50841), the AARP Andrus Foundation, and the National Institute of Aging (AG07476). 
(5) providing associative structures in memory; (6) group differentiation; and (7) individual differentiation. Much of what follows is based on and derives from empirical findings, both from my own work and from the work of others. But at several junctures, I have allowed myself to move beyond the data and engage in what is clearly speculative thinking about matters of both form and function. For these forays into the realm of the conjectural, I beg the reader's indulgence-there is still much that is not known about the intrapersonal functions of emotion and it is compelling to try to fill in the gaps to present a more complete, and, I hope, more testable, model.

\section{DESIGN OF THE HUMAN EMOTION SYSTEM}

Is the human emotion system a masterpiece of design or the ultimate kludge? This conundrum results from the fact that of all of the building blocks that make up human beings, some of the evolutionarily oldest as well as some of the newest are found in the emotion system. This confluence of old and new makes for an extremely complex system, one that often serves us extremely well as we navigate the stresses, challenges, and opportunities of life, but at other times bedevils and plagues us, even undermining our health. In this paper, I will present a two-system model of emotion and relate th is design to the major intrapersonal functions that a small set of "basic" emotions serve. In the design of any complex system, form and function are intimately intertwined and ultimately codetermined. Thus, to understand the functions of emotion, one must consider the design of the emotion system and vice versa. Here, I start by considering the basic design.

Many human systems need to only do one thing, but need to do it exceedingly well across the entire lifespan. The human heart is a prime example of this kind of highly specialised system. Designed to circulate blood and nutrients to the rest of the body, the four-chambered human heart is a masterpiece of simplicity of design. It is a powerful and durable muscle that contracts approximately once per second, with a system of simple valves that controls the direction of blood flow through its chambers. It has two primary operating parameters that can be altered in response to changing bodily demands: It can beat faster and it can beat harder. Over the course of an average lifetime, an average heart will go through its sequence of contracting and relaxing approximately 2.5 billion times, pumping tens of billions of gallons of blood. The heart is superb at pumping blood but it is not very good at allocating blood. Faced with the constantly changing demands of the various parts of the body that depend on it, the heart can only increase or decrease its overall output and cannot do much about distributing resources among these 
competing demands. To serve this latter need, there is a much more complex vascular system capable of differential action throughout the body, augmented by other systems that regulate blood volume, blood chemistry, blood oxygenation, and the like. Compared to the heart, these auxiliary control systems have a much larger number of operating parameters and are capable of much finer degrees of adjustment in response to the ever-changing demands of the organism.

These kinds of two-system schemes-simple, powerful core systems that do a limited number of things exceedingly well, surrounded by sophisticated and complex control mechanisms-constitute a very powerful design metaphor. Found in places as disparate as the human cardiovascular system and in modern reduced instruction set computers (where the central processing unit does only a few simple things but does them blazingly fast, and additional controls are implemented in complex and highly flexible software), two-system designs have the advantage of being capable of high levels of adaptability while maintaining a core "failsafe" system designed to keep on doing the most essential work no matter what.

\section{HUMAN EMOTION: A TWO-SYSTEM DESIGN}

The human emotion system lends itself to description in terms of a twosystem design, with the two systems contributing differentially to the various intrapersonal and interpersonal functions that emotions serve. At the core of the emotion system is a remarkably durable, simple, and efficient "processor", designed early in evolution to cope effectively with a few very basic, ubiquitous problems (e.g. Ekman, 1992; Lazarus, 1991; Levenson, 1994; Tooby \& Cosmides, 1990) in time-tested, highly predictable, and quite automatic (e.g. Zajonc, 1984) ways. Surrounding this core system is a more recently evolved, highly flexible, and much less predictable set of control mechanisms that are designed to influence the actions of the core system. Whereas the core system is largely hard-wired and not capable of major modification in response to experience, the control mechanisms are exquisitely sensitive to learning, fine-tuning their operating parameters across the course of life. Importantly, the basic integrity of the core system is not compromised in this design-the core system continues doing what it is designed to do throughout the lifespan. The influence of the control system is effected largely outside of the core. The control system acts on the "input" to the core system by altering the conditions that set the core system into action (e.g. Lazarus, 1991; Scherer, 1984; Smith \& Ellsworth, 1985), and it acts on the "output" of the core system by intercepting tendencies to respond to prototypic situations in characteristic, stereotypical ways and modulating the translation 
between response tendencies and resultant behaviours (e.g. Ekman \& Friesen, 1969; Hochschild, 1979). ${ }^{1}$

\section{THE CORE SYSTEM: ORCHESTRATING RESPONSES TO PROTOTYPICAL CHALLENGES}

The core emotional system in humans shares a number of features in common with emotional systems in infra-human species insofar as they evolved to solve a set of elemental problems (e.g. Ekman, 1992; Lazarus, 1991; Levenson, 1994; Tooby \& Cosmides, 1990) that are fairly common to all species as they interact with their external environment, with conspecifics, and with members of other species. The core system has all of the capabilities necessary for processing incoming information ${ }^{2}$ continuously and for detecting a small number of prototypical situations that have profound implications for the organism's immediate well-being and long-term survival. Having recognised in the stream of incoming perceptual information the configuration of features that defines one of a small number of prototypical situations, the core system activates an emotion, which is comprised of a set of response tendencies that have been selected by evolution for their high probability of dealing successfully and efficiently with the problems posed by that particular situation. The configural features of the prototypical situation and the exact features of the response package that is recruited differ from species to species (e.g. differences across species in what constitutes a predator and in the acoustic qualities of a fear vocalisation), but the basic purpose and operation of the core system is the same (i.e. matching environmental events to prototypes; recruiting and orchestrating the appropriate response).

${ }^{1}$ A number of other two-system views of emotion have been postulated. Dimensional views of emotion, many of which emphasise competing processes, such as approach and avoidance (e.g. Davidson, 1992) or appetitive and aversive processes (e.g. Lane, Reiman, Bradley, \& Lang, 1997; Lang, Bradley, \& Cuthbert, 1990), continue to exert a major influence in contemporary emotion theory and research. These models focus on how emotions are organised along primary dimensions and then search for the neural substrates of those dimensions. Two-system models that emphasise different functional qualities of emotion, more a long the lines of the model I have presented, have also been proposed. These include Gray's (1986) behavioural activation and behavioural inhibition systems and LeDoux's (1994) Type I (immediate, elicited, species-specific) and Type II (emitted, individual-specific) emotional responses. Currently, there are simply insufficient data available to enable us to choose among the competing models-each seems to account for at least some of what we know about some functions of some emotions under some conditions.

2 The "world" that is monitored may include the external world (e.g. approaching predators), the internal bodily milieu (e.g. vestibular imbalances, pain), and, in humans, the internal world of images and memories. 


\section{Elements of the Response Package}

For humans, the response package is crafted from a number of disparate elements, drawn from a palette that may include perceptual/attentional systems (e.g. Mathews \& Bradley, 1983), gross motor behaviour, purposeful behaviour (e.g. Frijda, 1986), expressive behaviour (e.g. Ekman, 1984; Izard, 1971), gating of higher mental processes (e.g. Bower, 1981), and physiological support (e.g. Davidson, Ekman, Saron, \& Senulis, 1990; Levenson, 1992). These elements and their functions are depicted in Table 1.

In terms of the response package, each emotion consists of a set of instructions that assembles a time-tested "recipe" of the elements of the response package in their proper proportions, with each element properly choreographed in terms of the timing of onsets, durations, and offsets. This response package, with both its constituent elements and choreography, has been selected by evolution as being most likely to solve the particular problem confronting the organism.

\section{Prototypical Events and Associated Emotions}

The core emotional system is located in the large box in the schematic representation in Fig. 1. This model is based on the assumption that evolution has provided us with a small set of emotions that activate

TABLE 1

Elements of the Response Package and their Functions

Element of Response Package

Perceptual/Attentional systems

Gross motor behaviour

Purposeful behaviour

Expressive behaviour

Gating of higher mental processes

Physiological support
Functions

Adjustments of perceptual thresholds and breadth of attentional field to maximise attention to challenging events and minimise attention to distracting, irrelevant events

Postural adjustments, changes in muscle tonus appropriate for ensuing purposeful behaviour

Fixed-action patterns, alteration of behaviour hierarchies that aid in coping with the challenging event Facial displays, alterations in voice tone, utterances that serve to signal intended action and to communicate to conspecifics

Limiting novelty of response, accessing associated memories to maximise probability of accessing successful, time-tested responses to challenging events Autonomic, central, endocrine, and other physiological adjustments optimal for supporting the organism's response to the challenging event 


\section{Antecedent conditions}

Recruited

response

tendencies

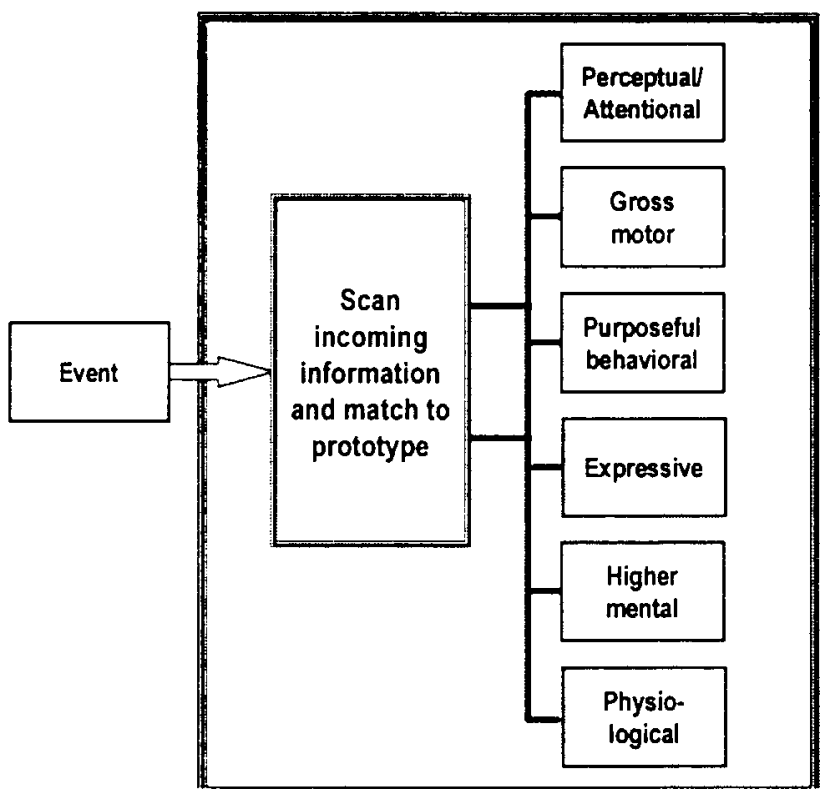

FIG. 1. The core emotional system.

hard-wired packages of response tendencies (e.g. the "affect program" in Tomkins, 1962). These response packages have a high probability of dealing successfully with certain prototypical situations that have significant implications for our well-being and survival. It is impossible to know how many of these "situation-emotion" pairs there are, ${ }^{3}$ but a list of likely pairs is presented in Table 2 .

An important design feature of the core system is its automaticity. When the stream of events matches one of the prototype situations, the associated emotion and its attendant set of response tendencies are elicited automatically, without additional conscious intervention (Zajonc, 1984). Thus, if in the stream of perceived events, the requirements for the prototype for "loss" are met, "sadness" will be the emotion elicited and it will recruit a set of response tendencies in the six domains listed earlier that are

\footnotetext{
${ }^{3}$ Clearly, this set of emotions does not constitute the entire human repertoire-for we are capable of having many other emotions that are not as hard-wired, not linked to such prototypical elicitors, and not associated with such fixed patterns of response.
} 
TABLE 2

Prototype Situations and Associated Emotions

\begin{tabular}{ll}
\hline Prototype Matched & Emotion Activated \\
\hline Loss & Sadness \\
Gain & Happiness \\
Satiation & Contentment \\
Cheating/Harm & Anger \\
inflicted & \\
Decay & Disgust \\
Danger/Threat & Fear \\
\hline
\end{tabular}

optimal for dealing successfully with loss. Of course, we have not yet worked out the complete set of response tendencies associated with each human emotion, but a possible set of response tendencies for "sadness" is presented in Table 3.

If the core system were the entire story, human emotions would be predictable and invariant. Under this scenario, as long as the events met the formal requirements of one of the prototypes (and also met some minimal perceptual criteria for intensity, sharpness of onset, and duration), the event would lead to the associated emotion along with its attendant response tendencies. However, even the most casual observation will reveal that not all losses lead to sadness, and not all sadness is accompanied by crying, sad facial expressions, racing hearts and the like. Clearly, there must be other factors at work.

TABLE 3

Elements of Response Package and Associated Response Tendency

Element of Response Package Response Tendency

Perception/Attention

Lowered threshold for perceiving other losses, narrower attentional field

Gross motor

Purposeful behaviour

Expression

Higher mental processes
Slumped posture, low muscle tonus, downturned gaze Seeking solace from others, attempting to replace lost person or object

Sad facial expression: Eyebrows raised in middle, downturned lip corners; voice tone softer and lower, speech rate slower

Reminiscences related to lost person or object; activated associations to other sad events 


\section{THE CONTROL SYSTEM: MODULATING EMOTION VIA APPRAISAL AND DISPLAY/FEELING RULES}

Consider a simple emotional core system designed to do a few things exceedingly well, to choose automatically precisely those responses in critical situations that have the highest likelihood of success, and to spare us the time-consuming processes of deliberation and planning. Is this the kind of emotion system we need? The answer is sometimes yes and sometimes no.

Imagine the proverbial tiger jumping out of its proverbial tree and landing in our proverbial path. If this event is quickly matched to the "threat" prototype, and if our entire being is then taken over by the core system's "fear" response package, and we find ourselves running away, vocalising in ways that would warn others of the danger and stimulate them to bring aid and assistance, having our heart racing and blood directed toward the large muscles of locomotion, all without a moment wasted in superfluous thought, then we are clearly being well-served. This situation illustrates one of the virtues of having a simple, core emotion system.

However, consider a situation in which we are waiting to merge from two lanes into one lane at a toll booth and another driver violates the norm of turn-taking, thus matching our "cheater", prototype (Tooby \& Cosmides, 1990). If we find our face engorged with blood, our voice screaming in rage, and our foot instinctively pressing on the accelerator causing our car to ram into the back of the offending vehicle, then clearly our simple, core emotion system has not served us well.

In our modern world, tigers rarely jump into our paths, people rarely steal our food, and conspecifics rarely threaten to kill our young. Instead of being confronted by these kinds of clear-cut primordial threats to our well-being, we instead encounter many smaller threats. These smaller threats may be sufficient matches to prototype to activate our core emotion system but they really do not require massive mobilisation of our emotional response systems. Rather, living with others with some degree of interpersonal harmony makes it imperative that we reserve our full-blown emotional responses for only the most critical and dangerous situations.

Not all species are endowed with control mechanisms that can alter the course of the core emotion system. In this regard, however, humans are richly (some might argue too richly) endowed. We have evolved an elaborate set of additional brain structures that can act to control our core emotion system in two primary ways: (1) changing the ways we appraise incoming information; and (2) inhibiting the transition between tendencies to respond in a given way and the actual responses we produce. 
Although the neuroanatomical substrates for th is control system are still not fully known, the functional implications can clearly be observed. An event that by all accounts should activate the prototype for a given emotion is reappraised in such a way that it no longer quite matches the prototype (e.g. we devalue an acquaintance who has died and thus this event no longer exactly matches the prototype for "loss"). Or an event matches the prototype for an emotion and the associated response tendencies are activated, but we inhibit their expression (e.g. we become angry at the cheating motorist but take our pedal off the accelerator and do not allow ourselves to ram into the offender's car).

\section{Structure of the Control System}

Structurally, the control system encapsulates the core emotion system so that it can act both on inputs and outputs as depicted in Fig. 2. The hardwired core emotion system can be viewed as being embedded between two learned control mechanisms (see also Heider's, 1991, notion of "frames"). On the input side, the control mechanism acts by altering the appraisal of events, thus changing the likelihood of their matching the prototype for activating the core emotion system. On the output side, the control mechanism acts by altering response probabilities, thus changing the likelihood of an activated response tendency resulting in an actual, observable response. There is evidence that these two kinds of controls exact different costs from the organism. For example, in a series of studies we (Gross \& Levenson, 1993; Gross \& Levenson, 1997) found that subjects could effect output-side suppression (i.e. reduce the behavioural manifestations of emotion), with little effect on their subjective emotional experience, but with significant activation of sympathetically mediated cardiovascular systems (we interpreted these autonomic changes as indicating that stopping the behavioural manifestations of an emotion once the core system has been activated involves significant effort and thus exacts a substantial metabolic cost). On the other hand, input-side suppression (i.e. telling subjects to reappraise an emotion-eliciting situation) reduces behavioural manifestations of the emotion as well as subjective emotional experience without exacting this large physiological cost (Gross, 1998). This supports the efficacy and relatively low metabolic cost of using reappraisal as a means to control emotion. Unfortunately, emotion-eliciting events do not always lend themselves to this kind of intervention early in the course of an emotion's onset-in many situations the more costly output-side suppression may be the only option.

It should be noted that emotion control mechanisms can both increase and decrease the associated probabilities of response. We often think of an emotion control system as being exclusively inhibitory, because that is the 


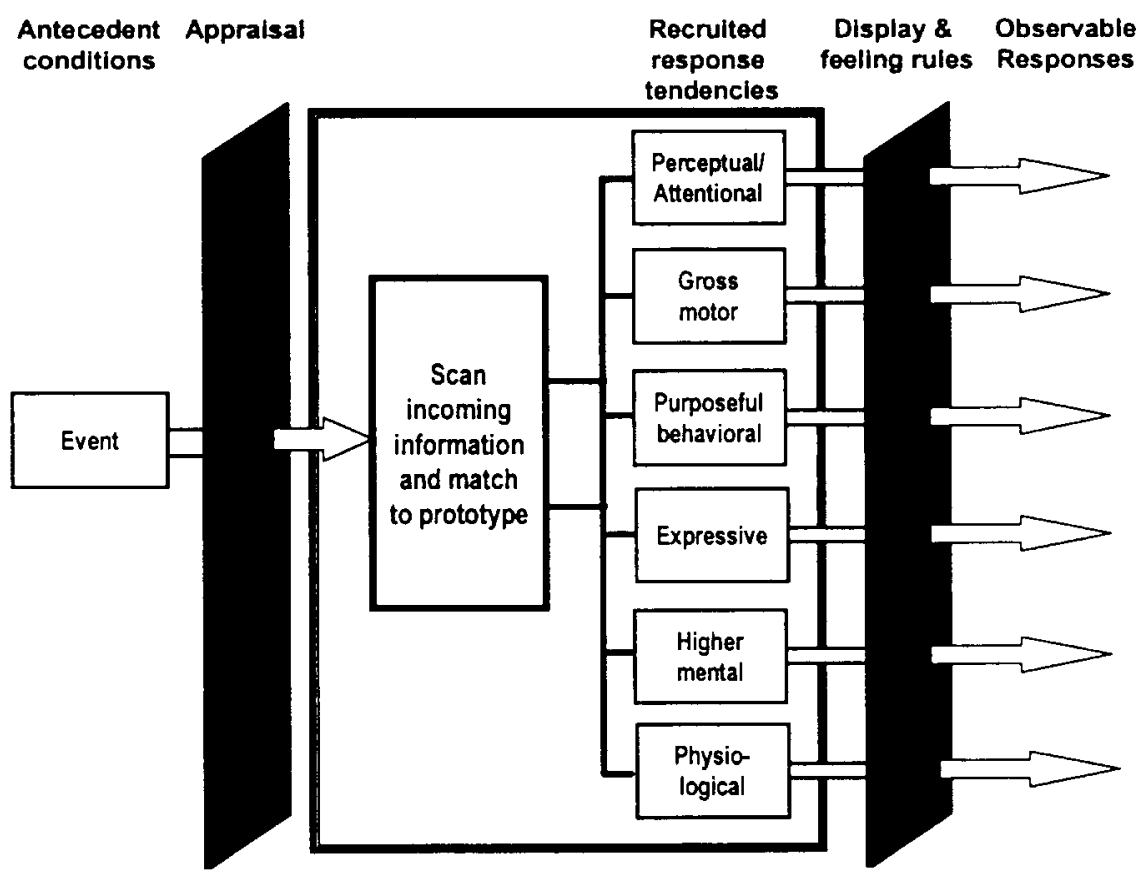

FIG. 2. The core emotional system and the control system.

function that most often serves the needs of preserving social harmony. However, an excitatory influence is also possible. Thus, for example, although the appraisal mechanism can make a clear threat appear much less threatening, it can conversely turn the most benign event into one that is perceived as highly threatening. Likewise, output-side controls can act to reduce the likelihood of a person smiling when the core system for happiness has been activated, or can increase the likelihood of smiling beyond that which would naturally occur when this particular emotion is elicited.

\section{Feedback and Re-entrancy: The Missing Arrows}

For the sake of clarity, I have presented a much simplified model of emotion, one that might appear to imply that the "flow" of emotion occurs only in one way, starting with "events" and ending with "responses". In reality, the emotion system is much more complex, having both feedforward and feedback mechanisms at all stages. In addition, one of the most intriguing qualities of human emotion is that it can be initiated both by events external to and internal to the individual (Izard, 1993). In fact, all of the major systems typically thought to be part of the emotional "response" can also function to initiate emotion. In our work we have shown how certain 
emotion-like facial movements can in it iate subjective emotional experience and autonomic nervous system activity (Levenson, Ekman, \& Friesen, 1990), whereas others have shown how autonomic arousal by itself can produce emotional experience (M arshall \& Zimbardo, 1979). Initiation of emotion by gross motor activity formed a central tenet of the James-Lange (James, 1884) theory of emotion. And, it is well-established that emotions can be initiated by higher mental processes such as imagery and recalled memories (e.g. Ekman, Levenson, \& Friesen, 1983; Lang, 1979).

A full model of emotions would also allow for re-entrant qualities, in that emotions beget secondary emotions, or emotions-about-emotion (e.g. Tomkins, 1962), with these secondary emotions often starting before the primary emotion has ended. Thus a person might show fear in response to a sudden loud noise and then become quite embarrassed about responding in that way. Emotions regularly occur in chains rather than as single discrete events, especially when they occur in interpersonal contexts.

\section{Emotional Regulation and Development}

The interactions between the core emotion system and the control mechanisms are not static, but rather change over time. The interplay between these systems-balancing between instinctive impulses to respond in fixed ways in certain well-defined situations, and the rich learning about the meaning of events and the consequences and appropriateness of emotion-related behaviours-combine to form the essence of "emotion regulation". A though definitional issues abound (Thompson, 1994), in my view emotion regulation refers to the lifelong process of work ing out an etiquette of action and interaction between the two emotion systems. By this I mean allowing the core system sufficiently free reign so that it can serve its basic adaptive functions, while maintaining sufficient controls so as to minimise the potential negative effects (and maxim ise the positive effects) that unrestrained emotions can have on the individual and on others. This process begins at the start of life as the infant learns to ga in control over powerful emotions such as distress, anger, and fear (e.g. Thompson, 1991). It continues through the socialisation process of childhood and the emerging importance of sexuality in adolescence and young adulthood. And it is sustained throughout adulthood and into very old age, when people struggle to maintain emotional equilibrium in the face of powerful losses that would, if left unregulated, lead to profound sadness and despair (e.g. Cartensen, Gross, \& Fung, 1998). Thus, just as the capacity of emotions to recruit and organise response tendencies is maintained across the lifespan (e.g. Levenson, Carstensen, Friesen, \& Ekman, 1991), it appears that achieving competence in emotion regulation is also a lifelong task (Carstensen, 1995; Gross, Carstensen, Pasupathi, \& Tsai, 1997). 
Finally, it is worth noting that the interplay between these two emotion systems is one of the defin ing characteristics of the human condition, which may account for the fascination it has had for philosophers (e.g. the battle between rationality and the passions), psychologists (e.g. "the mind-body problem"), poets, writers, and other artists throughout the ages.

\section{INTRAPERSONAL FUNCTIONS OF EMOTION}

With this model in mind, I now turn to a more detailed description of some of the most important intrapersonal functions of emotion.

\section{Coping with Environmental Challenges: Escape from Homeostasis}

A though humans can adapt to a wide range of external environments, they need to maintain their internal bodily environment with in a quite narrow range if they are to survive. Because of this, a significant proportion of the activity of the human nervous system is devoted to the task of maintaining a constant, optimal internal bodily milieu. This is particularly true of the autonomic nervous system, which is involved in regulating vital aspects of th is milieu including internal temperature, blood pressure and volume, and a number of important aspects of the body's chemistry (e.g. insulin release). Because of the narrow range of variation in these parameters that humans can tolerate, strong evolutionary pressures must have been brought to bear to select and strengthen these homeostatic mechanisms. There are many virtues to being able to maintain a steady-state, constant bodily milieu, but the benevolence of homeostasis would quickly become tyrannical if there was no way to allow the organism to have the brief excursions away from homeostasis that are necessary to deal with changing environmental demands (e.g. a way to have blood pressure increase beyond "normal" levels when extra oxygen and nutrients are needed by muscles being used to ward off attackers).

Viewed in this context, emotions can serve as a "temporary antidote" for homeostasis, providing the organism with a means for rapidly moving the internal environment away from its normative state, escaping the bonds of highly regulated centre-seeking systems, to create a bodily state that is optimal for dealing with a particular kind of threat or challenge. Emotions, such as anger, fear, and disgust, clearly serve this function. Anger and fear can increase cardiovascular levels far beyond those thought to be optimal for the organism's long-term survival, but which are optimal for the shortterm needs of actively dealing with threatening environmental challenges. D isgust may constrict a ir passages, increase the sensitivity of the gag reflex, and generally create a set of conditions that are nonoptimal for the long- 
term goal of taking in food and oxygen, but which serve the short-term goal of rejecting noxious and harmful substances. This function of escaping from homeostasis, cannot be applied to all of the basic emotions. Applying it to sadness, for example, is a bit of a stretch, and it does not seem to be a viable model for the function of the positive emotions (see later).

It is clearly a virtue to have a design feature that provides the organism with a way of temporarily overriding homeostatic forces, thus allowing adjustments to be made that are optimal for dealing with external threats. But, we can certainly have too much of a good thing. Emotions that have the capacity to counteract homeostasis and thus to allow large physiological excursions are also thought to have a long-term potential for damaging the organ systems they control. Thus, prolonged bouts of anger, fear, or sadness repeated chronically are thought to contribute to the aetiology of coronary artery disease, hypertension, gastric syndromes, headaches, and the like (e.g. Pennebaker, 1995; Spielberger et al., 1991; Tucker \& Friedman, 1996). Clearly, the organism is best served when homeostatic forces hold sway most of the time and the major excursions associated with negative emotions are relatively short and infrequent.

\section{Return to Homeostasis: The "Undoing" Function of Positive Emotions}

Most theoretical accounts of emotion take a "one-size-fits-all" approach, providing an overarching model that, by implication, accounts for all emotions. However, this often leads to models that fit some emotions well and others quite poorly. The functional account of emotion that I am proposing in this paper is typical in its assertion that emotions are associated with different patterns of action or "motor programs" (Frijda, 1986), which represent modes of behaviour that function to solve elemental problems or challenges in the organism's environment. In such accounts, "fear" is associated with the action pattern of "flight", "anger" is associated with "fight", and so on. Recruitment of response systems is seen as serving the needs associated with the action pattern. Thus, "fear-flight" calls forth additional cardiovascular output to provide necessary support for running behaviour. This kind of model works well until the positive emotions are considered. Thus, for example, it is not immediately obvious what elemental problem "happiness" solves and it is not at all clear what action pattern or motor program is associated with this emotion. Perhaps what is needed is not a single theory of emotion, but rather a set of emotion theories for different families of emotions (e.g. one theory for the negative emotions, one for the positive emotions, one for the self-conscious emotions, and one for the aesthetic emotions). 
I first became interested in this problem when studying the autonomic correlates of different emotions. Whereas basic negative emotions, such as anger, fear, sadness, and disgust, were all associated with significant autonomic activation, positive emotions, such as happiness, amusement, and contentment, did not seem to move autonomic levels away from their baseline states (e.g. Levenson et al., 1990, 1991). ${ }^{4}$ What then were the functions of these positive emotions?

One important function associated with positive emotions appears to revolve around "soothing" behaviours. This soothing function can be seen early in life as parents try to calm their distressed infants by making funny faces, holding, rocking, talking with mellifluous tonality, and singing. These parent-child scenarios, which typically start with a distressed child, suggest that positive emotions may have important functions associated with quelling prior states of arousal associated with negative emotions. In an early paper, I speculated that an important function of certa in positive emotions might be to "undo" the prior arousal associated with negative emotions (Levenson, 1988).

Negative emotions, of course, eventually run their course, and thus an alternative strategy for dealing with a distressed infant might be to ignore rather than sooth (e.g. letting a baby cry himself to sleep). But negative emotions left "unsoothed" have a tendency to beget more of the same and it is not unusual for volleys of unquelled negative emotions to extend over quite long periods of time. If negative emotions represent an "escape from homeostasis", as argued earlier, then perhaps nature has also provided us with a tool in the form of certain positive emotions that serve to hasten the "return to homeostasis". Thus, when we find ourselves in a state of lingering negative emotional arousal, positive emotions such as joy, amusement, and contentment may function to short-circuit the process, giving homeostatic mechanisms a boost and quickly shunting us back to the preemotional state of arousal.

To test this notion, we (Fredrickson \& Levenson, 1998) conducted an experimental study and a correlational study in which we measured how long it took subjects who were in the throes of a prior negative emotional state to return to baseline levels of cardiovascular arousal. In the experimental study we compared the natural time course of fear-related arousal (using a fear stimulus followed by a neutral stimulus) to the time course when fear was followed by another negative emotional stimulus (sadness) or by one of two positive emotional stimuli (contentment or amusement). In the correlational study, we determined how long it took subjects who

\footnotetext{
${ }^{4}$ The only exception being when these positive emotions are accompanied by behaviours associated with sharp alterations in breathing (e.g. laughter), in which case substantial autonomic activation does occur.
} 
were experiencing sadness to return to baseline, comparing those who spontaneously smiled with those who did not. In both studies, the positive emotions clearly hastened the speed at which subjects returned to baseline cardiovascular levels.

This "undoing" function of positive emotions such as contentment and amusement provides humans ${ }^{5}$ with a powerful tool to counteract the potentially harmful effects of unduly sustained negative emotions. This function adds an important symmetry to the emotional system, with the negative emotions acting to help the organism escape from homeostasis and these positive emotions abetting a more rapid return to homeostatic levels. The undoing function provides a means for soothing that is in it ially applied by the caregiver but that increasingly comes under the control of the individual. This soothing takes several forms. There is an almost automatic version such as when amusement directly follows fear or disgust (e.g. fear followed by laughter when riding a roller coaster, or disgust followed by laughter when watching gory movies; Tomkins, 1962). And there is also a much more intentional and purposeful version such as when married couples introduce positive emotions (e.g. affection) as a way of defusing the physiological and emotional arousal associated $w$ ith escalating negative emotional exchanges (Carstensen, Gottman, \& Levenson, 1995; Gottman \& Levenson, 1986). ${ }^{6}$

\section{Shifting Behavioural and Cognitive Hierarchies: Organiser or Disorganiser?}

Emotion appears to function as a master choreographer, the ultimate organiser of disparate response systems. Emotion orchestrates the action of multiple response systems so that they act in a unified way in the service of solving fundamental problems. This view of emotion as an organiser stands in stark contrast to the oft-expressed view of emotion as a disorganiser or disrupter. In this latter view, emotion is the enemy of purposeful behaviour and rational thought. So which is it-is emotion an organiser or a disorganiser?

\footnotetext{
${ }^{5}$ It is unclear whether a similar function exists in infrahuman species as well. Positive emotions in other species are often ascribed to states of play (e.g. Panksepp, 1993), but play seems more like a high arousal state than one associated with a return to homeostasis. Perhaps a closer equivalent can be found in grooming behaviours, which are arguably "pleasurable" and which may have a soothing effect on the individual and on the dyad.

${ }^{6}$ Positive emotions may have other important functions as well. Fredrickson (1998) has described how positive emotions serve to broaden our thought-action repertoires. Isen (1990) has shown how positive emotions increase creative problem-solving abilities and cognitive flexibility.
} 
The answer to this question is that both are partially true. One of the basic functions of negative emotions in the model I have presented is to activate time-tested responses and to create a bodily milieu that will have the highest probability of dealing successfully with fundamental threats and problems. In serving this function, time is of the essence, thus false or wasted actions and thoughts are the enemy. Under the influence of a negative emotion, ongoing complex behaviours and thoughts are interrupted and replaced unceremoniously with a simple, bare-bones behavioural and cognitive state. Swept up in the throes of a strong emotion, it becomes very difficult to persist in (and sometimes even to remember) what was going on beforehand. Viewed from the perspective of what we were trying to accomplish prior to the emotion taking hold, the subsequent emotional behaviour may appear chaotic and disorganised. But, viewed from the perspective of the survival of the organism, the emotional behaviour represents an elegant, adaptive, and highly organised state of affairs.

For emotion to have the capacity to pre-empt ongoing thought and behaviour, there must be interrupt/override mechanisms built into the system. Like an interrupt in a modern computer, certain very simple, basic processes (e.g. clock ticks, mouse movements) are assigned the highest priority - when they occur, their needs are serviced immed iately and everyth ing else must wait. In humans, we usually think of control mechanisms existing at higher cortical levels and acting downward toward lower brain centres. But in the case of emotion, control also needs to be asserted upward such that ongoing cognitive and behavioural activity can be gated or interrupted and replaced by the response package associated with the activated emotion.

\section{Subjective Experience: More than Mere Epiphenomenon?}

One of the most intriguing aspects of emotion is the subjective feeling state that accompanies states such as anger and sadness. Precisely describing the qualities of these subjective experiences turns out to be a quite difficult task for the person untrained in phenomenological inquiry. In contrast, people seem much more adept at knowing which emotional state they are experiencing (a fortunate state of affairs for those who regularly ask such questions of their experimental subjects). Thus, it might be fairly said of one's subjective experience of emotion: "I can't describe it in words, but I know it when I feel it".

The issue of what is responsible for subjective emotional experience has a long history (Averill, 1994; Izard, 1993). My own view is neo-Jamesian, namely, that the subjective experience of a given emotion derives largely from the sensations that are generated by the activation of the associated response package. Thus, in sadness the subjective experience incorporates sensations from the heart, from certain patterns of breathing, from stereo- 
typical contractions of the facial muscles, from a sense of change in the perceptual and attentional fields, etc. None of these sensations is very precise (Pennebaker, 1982), and we lack precise structures in language to describe them. For this reason, we often resort to metaphors to describe subjective emotional experience ("I feel like I'm about to explode"). Lakoff (1993) has described metaphors as ways of translating between different domains of thought and experience, a definition that seems particularly apt when applied to the realm of emotion. Despite the lack of precision inherent in the sensations derived from these response systems, it is interesting to note how much specificity there is in our use of emotional metaphors. When it comes to these metaphors, we match much more than we mix. Thus, for example, when angry we might say we feel on the edge of "exploding" or "blowing my top", but these metaphors would almost never be used if we were feeling sad, or fearful, or disgusted.

Regardless of its source, I believe a primary function of subjective emotional experience is to serve as a signal that helps us to engage in adaptive voluntary behaviours. Once the initial emotional "surge" has passed, along with its attendant almost automatic behaviours, the lingering subjective feeling helps us to clarify the way we feel, to think and talk about the events that led to the emotion, to make future plans concerning these events (e.g. to avoid or pursue situations that might be productive of these emotions), to share our feelings with others in ways that will elicit additional support from them, and to describe our feelings in ways that will cause others to alter their behaviours.

Subjective emotional experience also plays an important role in learning via both classical and operant conditioning. In operant conditioning, subjective emotional experience is seen as having reinforcing qualities. Pleasurable emotional experience is positively reinforcing, thus increasing the likelihood of our engaging in behaviours that lead up to it. Negative emotional experience may be negatively reinforcing, thus increasing the likelihood of our engaging in behaviours that enable us to avoid it. In classical conditioning, subjective emotional experience is seen as an unconditioned response to certain stimuli (e.g. feeling disgusted when seeing and smelling spoiled food) which can become the conditioned response to other contiguous stimuli (e.g. the person who gave us the food). This has the potential for creating quite complex and rich associations between environmental cues and subjective emotional experience.

\section{Providing Associative Structures in Memory}

In the throes of a strong emotion, we often find ourselves awash in memories of other times when we had the same emotion. Thus, for example, experiencing sadness at the loss of a loved one, a person might 
remember other losses that had occurred earlier in life. Some of these elicited memories may seem to have been "forgotten", not being accessible prior to the emotional event. The fact that emotions act as magnets for like memories has led to speculation about the role that emotions play in the storage and accessing of events in memory. Bower's (1981) theory of mood and memory is a sophisticated model of how such a system might function. What is not clear, however, is whether this accessing of like-emotional memories serves a useful function in the organism's attempts to deal with problematic situations. One possibility is that it provides access to a set of additional experiences and outcomes that can be used in planning reasoned and thoughtful responses to help cope with the residual elements of the eliciting situation. Thus, after the immediate "emergency" has been dealt with by the highly generalised "solution" associated with an emotion, longer-term coping plans can be formulated with access to a corpus of highly individualised experiences and knowledge derived from a lifetime of similar emotional experiences.

\section{Group Differentiation}

An important function of emotions, reflected in characteristics of both the core system and the control mechanisms, is the critical role they play in helping us make distinctions among people. This appears to be particularly true when we are dealing with differences among groups constituted on the basis of major sources of human variation such as gender, age, or culture. A simple thought experiment should help illustrate this point. Think about how men differ from women, or how the young differ from the aged, or how Chinese-Americans differ from Middle Americans. Then start listing the distinguishing features. It is almost impossible to make these kinds of distinctions without invoking emotional qualities that touch on the core system (e.g. threshold for eliciting emotion in general or for particular emotions) and the control mechan isms (e.g. means of dealing with challenging situations, tendencies to inhibit or exaggerate emotional expression). Thus, whether it is the fabled emotional lability of woman versus the emotional stability of men, the exuberance of youth versus the sobriety of age, the emotional restraint of the Chinese-American versus the emotional directness of the Middle American, the defining features of these categories (and of their associated stereotypes) draw heavily on emotional qualities. These kinds of notions beg two questions: (1) are emotional differences among groups "real"? and (2) if they are real, what are the bases of these differences?

The question of whether these kinds of emotional differences are "real" is an intriguing one. Where literatures have reached critical mass, reliable differences have been identified, some of which confirm stereotypes and 
some of which do not (e.g. see LaFrance \& Banaji, 1992, for a review of the literature on gender and emotion). For present purposes, it is important to note the ubiquity of notions concerning emotional differences among groups, regardless of whether they are commonly held or idiosyncratic, and ultimately true or false. These notions assume a fundamental place in our social cognitions, reflecting a basic way that we elaborate categories that help organise the large numbers of people that make up our social world.

If we assume for a moment that reliable emotional differences between groups do in fact exist, how might they come into being? Referring back to the two-systems model of emotion, such differences could be grounded in either system.

Sources in the Core System. In the core system, systematic differences could exist between groups in the required intensity and closeness to prototype required for events to match the prototypical situations that elicit different emotions. Thus, group A might require more intense threats that are closer to the idealised prototype to elicit fear than group B. Such differences could also occur in the relative and absolute strengths of the hard-wired connections to the various response tendencies. Thus, when the fear prototype is matched, group C's response tendencies could consist of substantial autonomic activation and little facial expression, whereas group D would tend toward substantial activation of both systems. Studies showing ethnic differences in infants' irritability, expressiveness, and temperament (e.g. Camras et al., 1998; Freeman, 1979) probably come as close to demonstrating these $\mathrm{k}$ inds of hard-wired core system differences as is possible using noninvasive measures (with the obvious caveat that these studies cannot eliminate the effects of prior emotional learning).

Sources in the Control Mechanisms. The control mechanisms involving appraisal and display and feeling rules are exquisitely suited to serve as repositories for emotional learning that is consistent within groups. We are constantly being "educated" and shaped about how to appraise the world, how much to display our emotions, what we "should" be feeling, and what we should say we are feeling in ways appropriate to our gender, age, and cultural heritage. Examples of the kinds of learnt lessons and proscriptions that could influence emotion control systems can readily be generated for appraisals ("the world is a dangerous place"), display rules ("don't let them see you sweat"), and feeling rules ("don't wear your heart on your sleeve"). To the extent that there are systematic differences across gender, age, and culture in the emotional lessons that are taught to and learned by group members, we would expect to find reliable emotionaldifferences among the groups. 


\section{Individual Differentiation}

Just as was the case in our discussion of group differences, when we think about the people we know and how they differ from each other, emotional qualities involving the core system and the control mechanisms quickly come to the fore. Interestingly, these differences are often expressed in terms of deviations from group norms (e.g. "he's very emotional for a man", "she's very sentimental given her youth", "he's very expressive for a Japanese"). As in these examples, individual differentiation by emotional characteristics often lacks specificity, couched in generalities about the intensity of emotion rather than about specific emotions or specific response systems, although the latter is also possible (e.g. "his entire life is governed by fear"; "her face is an open book").

Despite the apparent centrality of emotional concepts for distinguishing among individuals (and as indicated earlier, for groups as well), it is ironic that the currently favoured methods for assessing individual differences such as "Big Five" factorial models (e.g. Goldberg, 1990) do not make direct use of emotion terms to classify people. However, there appears to be a growing interest among personality researchers in developing more detailed understanding of how emotional qualities help distinguish among people both in terms of the Big Five and other models of personality (e.g. Gross, Sutton, \& Ketelaar, 1998; Larsen \& Diener, 1987; Larsen \& Ketelaar, 1991; Watson \& Clark, 1992). This work should add greatly to our understanding of the function of emotions in differentiating individuals.

\section{CLOSING THOUGHTS}

It is somewhat ironic to be writing a paper on the intrapersonal functions of emotion at a time when such increased emphasis is being placed on the interpersonal and communicative functions of emotion (e.g. Fridlund, 1994). There is a personal irony in this as well because a large portion of my empirical work on emotion has been concerned with studying emotion as it arises in interpersonal contexts such as in intimate relationships (e.g. Levenson, Carstensen, \& Gottman, 1994; Levenson \& Gottman, 1983). Emotion clearly has critically important interpersonal functions in regulating the distance between people (drawing us together and pushing us apart). Similarly, the various emotional response systems also have important interpersonal functions (e.g. the signalling function that facial expressions have for conspecifics). The fact that particular aspects of emotion serve both intrapersonal and interpersonal functions is yet another sign of a well-designed system, where individual features serve multiple functions. In a highly social species, 
such as humans, it makes good sense for the emotion system to be designed in ways that serve the needs of the individual as well as the needs of the group.

In this article I have tried to present a functional account of emotion that deals primarily with what are often called "basic" emotions. As the preceding discussion has indicated, even when dealing with such a small set of emotions, it is impossible to account for all of the functions of all of the emotions with a single unified theory. At the very least, the functions of the positive emotions have to be considered separately from those of the negative emotions. As other more complex (and extremely important) human emotions such as the self-conscious emotions (guilt, shame, pride, envy) and the aesthetic emotions are considered, additional models and theories may be necessary to account adequately for both the structural and functional features of these emotions (e.g. Keltner \& Buswell's, 1997, work on embarrassment). Evolution has endowed humans with an highly differentiated set of emotions, some of which are quite "old", shared with our infrahuman predecessors, and others of which are relatively "new", apparently unique to humans. This is an enormous investment of resources in one area of functioning, which underscores the central and critical role that emotions play in defining the human condition.

M anuscript received 2 March 1999

\section{REFERENCES}

Averill, J.R. (1994). I feel, therefore I am-I think. In P. Ekman \& R .J. Davidson (Eds.), The nature of emotion: Fundamental questions. Series in affective science (pp. 379-385). N ew York: Oxford University Press.

Bower, G.H. (1981). Mood and memory. American Psychologist, 36, 129-148.

Camras, L.A., Oster, H., Campos, J., Campos, R., Ujiie, T., Miyake, K., Wang, L., \& Meng, Z. (1998). Production of emotional facial expressions in European American, Japanese, and Chinese infants. Developmental Psychology, 34, 616-628.

Carstensen, L.L. (1995). Evidence for a life-span theory of socioemotional selectivity. Current Directions in Psychological Science, 4, 151-156.

Carstensen, L.L., Gottman, J.M., \& Levenson, R.W. (1995). Emotional behavior in longterm marriage. Psychology and Aging, 10, 140-149.

Carstensen, L.L., Gross, J.J., \& Fung, H.H. (1998). The social context of emotional experience. In K.W. Schaie \& M.P. Lawton (Eds.), Annual review of gerontology and geriatrics: Vol. 17. Focus on emotion and adult development (pp. 325-352). N ew York: Springer.

Davidson, R.J. (1992). Emotion and affective style: Hemispheric substrates. Psychological Science, 3, 39-43.

Davidson, R.J., Ekman, P., Saron, C.D., \& Senulis, J.A. (1990). Approach-withdrawal and cerebral asymmetry: Emotional expression and brain physiology. I. Journal of Personality and Social Psychology, 58, 330-341. 
Ekman, P. (1984). Expression and the nature of emotion. In K.S. Scherer \& P. Ekman (Eds.), Approaches to emotion (pp. 319-343). Hillsdale, NJ: Erlbaum.

Ekman, P. (1992). An argument for basic emotions. Cognition and Emotion, 6, 169-200.

Ekman, P., \& Friesen, W.V. (1969). The reperto ire of nonverbal behavior: Categories, origins, usage, and coding. Semiotica, 1, 49-98.

Ekman, P., Levenson, R.W., \& Friesen, W.V. (1983). Autonomic nervous system activity dist inguishes among emotions. Science, 221, 1208-1210.

Fredrickson, B.L. (1998). What good are positive emotions? Review of General Psychology, 2, $300-319$.

Fredrickson, B.L., \& Levenson, R.W. (1998). Positive emotons speed recovery from the cardiovascular sequelae of negative emotions. Cognition and Emotion, 12, 191-220.

Freeman, D.G. (1979). Human sociobiology: A holistic approach. New York: Free Press.

Fridlund, A.J. (1994). Human facial expression: An evolutionary view. San D iego, CA: Academic Press.

Frijda, N.H. (1986). The emotions. Cambridge, UK: Cambridge University Press.

Goldberg, L.R. (1990). An alternative "description of personality": The Big-Five factor structure. Journal of Personality and Social Psychology, 59, 1216-1229.

Gottman, J.M., \& Levenson, R.W. (1986). Assessing the role of emotion in marriage. Behavioral Assessment, 8, 31-48.

Gray, J.A. (1986). Anxiety, personality and the brain. In A. Gale \& J.A. Edwards (Eds.), Physiological correlates of human behaviour: Vol. 3. Individual differences and psychopathology (pp. 31-43). Orlando, FL: Academic Press.

Gross, J.J. (1998). Antecedent- and response-focused emotion regulation: Divergent consequences for experience, expression, and physiology. Journal of Personality and Social Psychology, 74, 224-237.

Gross, J.J., Carstensen, L.L., Pasupathi, M., \& Tsai, J. (1997). Emotion and aging: Experience, expression, and control. Psychology and Aging, 12, 590-599.

Gross, J.J., \& Levenson, R.W. (1993). Emotional suppression: Physiology, self-report, and expressive behavior. Journal of Personality and Social Psychology, 64, 970-986.

Gross, J.J., \& Levenson, R.W. (1997). H iding feelings: The acute effects of inhibiting negative and positive emotion. Journal of Abnormal Psychology, 106, 95-103.

Gross, J.J., Sutton, S.K., \& Ketelaar, T. (1998). Relations between affect and personality: Support for the affect-level and affective reactivity views. Personality and Social Psychology Bulletin, 24, 279-288.

Heider, K.G. (1991). Landscapes of emotion. Three cultures of emotion in Indonesia. Cambridge, UK: Cambridge University Press.

Hochschild, A.R. (1979). Emotion work, feeling rules, and social structure. American Journal of Sociology, 84, 551-575.

Isen, A.M. (1990). The influence of positive and negative affect on cognitive organization: Some implications for development. In N.L. Stein, B. Leventhal, \& T. Trabasso (Eds.), Psychological and biological approaches to emotion (pp. 75-94). Hillsdale, NJ: Erlbaum.

Izard, C.E. (1971). The face of emotion. New York: Appleton-Century-Crofts.

Izard, C.E. (1993). Four systems for emotion activation: Cognitive and noncognitive processes. Psychological Review, 100, 68-90.

James, W. (1884). What is an emotion? Mind, 9, 188-205.

Keltner, D., \& Buswell, B.N. (1997). Embarrassment: Its distinct form and appeasement functions. Psychological Bulletin, 122, 250-270.

LaFrance, M., \& Banaji, M. (1992). Toward a reconsideration of the gender-emotion relationship. In M.S. Clark (Ed.), Emotion and social behavior. Review of personality and social psychology, (Vol. 14, pp. 178-201). Newbury Park, CA: Sage. 
Lakoff, G. (1993). The contemporary theory of metaphor. In A. Ortony (Ed.), Metaphor and thought (pp. 202-251). New York: Cambridge University Press.

Lane, R.D., Reiman, E.M., Bradley, M.M., \& Lang, P.J. (1997). Neuroanatomical correlates of pleasant and unpleasant emotion. Neuropsychologia, 35, 1437-1444.

Lang, P.J. (1979). A bio-informational theory of emotional imagery. Psychophysiology, 16, $495-512$.

Lang, P.J., Bradley, M.M., \& Cuthbert, B.N. (1990). Emotion, attention, and the startle reflex. Psychological Review, 97, 377-395.

Larsen, R.J., \& Diener, E. (1987). Affect intensity as an individualdifference characteristic: A review. Journal of Research in Personality, 21, 1-39.

Larsen, R.J., \& Ketelaar, T. (1991). Personality and susceptibility to positive and negative emotional states. Journal of Personality and Social Psychology 61, 132-140.

Lazarus, R.S. (1991). Emotion and adaptation. New York: Oxford University Press.

LeDoux, J.E. (1994). The degree of emotional control depends on the kind of response system involved. In P. Ekman \& R.J. Davidson (Eds.), The nature of emotion: Fundamental questions (pp. 270-272). New York: Oxford University Press.

Levenson, R.W. (1988). Emotion and the autonomic nervous system: A prospectus for research on autonomic specificity. In H.L. Wagner (Ed.), Social psychophysiology and emotion: Theory and clinical applications (pp. 17-42). Chichester, UK: Wiley.

Levenson, R.W. (1992). Autonomic nervous system differences among emotions. Psychological Science, 3, 23-27.

Levenson, R.W. (1994). Human emotion: A functional view. In P. Ekman \& R.J. Davidson (Eds.), The nature of emotion: Fundamental questions (pp. 123-126). New York: Oxford University Press.

Levenson, R.W., Carstensen, L.L., Friesen, W.V., \& Ekman, P. (1991). Emotion, physiology, and expression in old age. Psychology and Aging, 6, 28-35.

Levenson, R.W., Carstensen, L.L., \& Gottman, J.M . (1994). Influence of age and gender on affect, physiology, and their interrelations: A study of long-term marriages. Journal of Personality and Social Psychology, 67, 56-68.

Levenson, R.W., Ekman, P., \& Friesen, W.V. (1990). Voluntary facial action generates emotion-specific autonomic nervous system activity. Psychophysiology, 27, 363-384.

Levenson, R.W., \& Gottman, J.M . (1983). Marital interaction: Physiological linkage and affective exchange. Journal of Personality and Social Psychology, 45, 587-597.

Marshall, G.D., \& Zimbardo, P.G. (1979). Affective consequences of inadequately explained physiological arousa1. Journal of Personality and Social Psychology, 37, 970-988.

Mathews, A., \& Bradley, B.P. (1983). Mood and the self-reference bias in recall. Behaviour Research and Therapy, 21, 233-239.

Panksepp, J. (1993). Rough and tumble play: A fundamental brain process. In K. MacDonald (Ed.), Parent-child play: Descriptions and implications. SUNY series, children's play in society (pp. 147-184). Albany, NY: State University of New York Press.

Pennebaker, J.W. (1982). The psychology of physical symptoms. New York: Springer.

Pennebaker, J.W. (1995). Emotion, disclosure, and health. Washington, DC: American Psychological Association.

Scherer, K.R. (1984). Emotion as a multicomponent process: A model and some crosscultural data. In P. Shaver (Ed.), Review of Personality and Social Psychology (Vol. 5, pp. 37-63). Beverly Hills, CA: Sage.

Smith, C.A., \& Ellsworth, P.C. (1985). Patterns of cognitive appraisal in emotion. Journal of Personality and Social Psychology, 48, 813-838.

Spielberger, C.D., Crane, R.S., Kearns, W.D., Pellegrin, K.L., Rickman, R.L., \& Johnson, E.H. (1991). Anger and anxiety in essential hypertension. In C.D. Spielberger, I.G. Sarason, Z. Kulcsar, \& G.L. Van Heck (Eds.), Stress and emotion: Anxiety, anger, and 
curiosity: Vol. 14. The series in clinical psychology and The series in stress and emotion: Anxiety, anger, and curiosity (pp. 265-283). New York: Hemisphere.

Thompson, R.A. (1991). Emotional regulation and emotional development. Educational Psychology Review, 3, 269-307.

Thompson, R.A. (1994). Emotion regulation: A theme in search of definition. Monographs of the Society for Research in Child Development, 59(2-3), 250-283.

Tomkins, S.S. (1962). Affect, imagery, consciousness: Vol. 1. The positive affects. New York: Springer.

Tooby, J., \& Cosmides, L. (1990). The past explains the present: Emotional adaptations and the structure of ancestral environments. Ethology and Sociobiology, 11, 375-424.

Tucker, J.S., \& Friedman, H.S. (1996). Emotion, personality, and health. In Carol Magai \& S.H. McFadden (Eds.), Handbook of emotion, adult development, and aging (pp. 307-326). San Diego, CA: Academic Press.

Watson, D., \& Clark, L.A. (1992). On traits and temperament: General and specific factors of emotional experience and their relation to the five-factor model. Special Issue: The fivefactor model: issues and applications. Journal of Personality, 60, 441-476.

Zajonc, R.B. (1984). On the primacy of affect. American Psychologist, 39, 117-123. 
Copyright of Cognition \& Emotion is the property of Psychology Press (T\&F) and its content may not be copied or emailed to multiple sites or posted to a listserv without the copyright holder's express written permission. However, users may print, download, or email articles for individual use. 